
DE PRATA A PARTIR DE RESÍDUOS ANALÍTICOS

\title{
STUDY OF THE SUSTAINABILITY IN THE OBTAINMENT OF SILVER NITRATE FROM ANALYTICAL WASTE
}

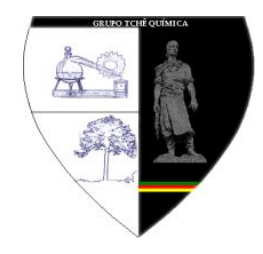

\author{
GRASEL, Fábio dos Santos ${ }^{1,2, *} ;$ FLORES, Bruna ${ }^{2} ;$ MEDEIROS, Geandra²; LAUSCHNER, \\ Elton André2; SOUZA, Adrielle Fontoura'; ${ }^{2}$ BARROS, Carla Giane ${ }^{2}$ \\ ${ }^{1}$ Instituto Federal de Educação, Ciência e Tecnologia do Rio Grande do Sul, Rua Princesa Isabel, 60, cep \\ 95770-000, Feliz - RS, Brasil \\ (fone: +55 5136374400 ) \\ ${ }^{2}$ Escola Estadual Técnica São João Batista, Curso Técnico em Química, Rua João Pessoa, 1468, cep 95780- \\ 000, Montenegro - RS, Brasil \\ (fone: +55 513632 2500) \\ ${ }^{*}$ Autor correspondente \\ e-mail: fsgrasel@gmail.com
}

Received 14 June 2018; received in revised form 09 August 2018; accepted 10 August 2018

\section{RESUMO}

A prata é um metal nobre e relativamente raro encontrado de forma natural na crosta terrestre. Este metal é muito utilizado na fabricação de diversos produtos de diferentes segmentos, entre eles joias, moedas, eletroeletrônicos, reagentes analíticos e fabricação de películas sensíveis para fotografia e radiografia. A grande geração de resíduos e a preocupação em relação à contaminação, por descarte inadequado de produtos perigosos tem sido um dos motivos para o estudo do reaproveitamento da prata e outros resíduos analíticos. Nesse projeto buscou-se a obtenção do nitrato de prata a partir de resíduos analíticos gerados em laboratórios. Foram utilizadas cinco diferentes rotas sintéticas para obtenção da prata metálica, sendo elas a redução por formaldeído, glicose, frutose, açúcar grau alimentício e zinco metálicos. O nitrato de prata obtido foi analisado a fim de calcular o rendimento e grau de pureza, onde se obteve resultados superiores a $96 \%$ de pureza, sendo possível se reciclar resíduos contendo prata, além de reagentes vencidos. O projeto apresentou ser sustentável e barato para a aplicação em instituições de ensino, diminuindo o volume de resíduos gerados e desenvolvendo conscientização ambiental.

Palavras-chave: resíduos analíticos, nitrato de prata, sustentabilidade, cloreto de prata.

\section{ABSTRACT}

Silver is a noble and relatively rare metal found naturally in the earth's crust. This metal is widely used in the manufacture of various products from different segments, among them jewelry, coins, electronics, analytical reagents and the manufacture of sensitive films for photography and radiography. The large generation of waste and the concern about the contamination by inappropriate disposal of dangerous products has been one of the reasons for the study of the reuse of silver and other analytical residues. In this project, we sought to obtain silver nitrate from analytical waste generated in the laboratories. Five different synthetic routes were used to obtain the metallic silver, being the reduction by formaldehyde, glucose, fructose, food grade sugar and metallic zinc. The obtained silver nitrate was analyzed to calculate the yield and degree of purity, where it obtained results superior to $96 \%$ of purity, being possible to recycle wastes containing silver, besides reagents expired. The project presented being sustainable and cheap for application in educational institutions, reducing the volume of waste generated and promoting environmental awareness.

Keywords: analytical residues, silver nitrate, sustainability, chloride silver. 


\section{INTRODUÇÃO}

A prata é um metal nobre e relativamente raro encontrado de forma natural na crosta terrestre. Este metal é muito utilizado na fabricação de diversos produtos de diferentes segmentos, entre eles joias, moedas, eletroeletrônicos, reagentes analíticos e fabricação de películas sensíveis para fotografia e radiografia (Kuya, 1993; Modi et al., 2012; Nakiboğlu et al., 2003; Ramirez et al., 2011).

A prata é um elemento químico puro, metálico, que no estado natural apresenta-se branco e brilhante. No sistema periódico dos elementos, pertence ao grupo de metais de transição e se enquadra na família do cobre e do ouro. Seu símbolo químico, $\mathrm{Ag}$, deriva de argentum (prata, em latim). Dúctil e maleável, de fácil manipulação química e mecânica, a prata é o metal de maior condutibilidade elétrica e calorífica. $\mathrm{Na}$ fabricação de dispositivos condutores, no entanto, a indústria dá preferência ao cobre, por ser mais econômico. A prata não oxida em contato com o ar, exceto quando ele contém gás sulfídrico, caso em que escurece. Quando polida, possui excelente capacidade de reflexão (Bendassolli et al. 2003; Modi et al., 2012; Nakiboğlu et al., 2003).

Nos últimos anos do século XX, o México, Peru, Estados Unidos e Canadá eram os grandes produtores mundiais. Somente a Rússia, com suas reservas nos Urais e na Sibéria, produzia quantidades comparáveis. O Brasil é importador de prata, pois sua produção, que provém do refino do ouro e das metalurgias de chumbo e zinco é pequena (ADVFN, 2018).

Com 0 crescimento acelerado do desenvolvimento industrial vem à geração elevada de produtos e serviços, que por sua vez acabam gerando resíduos provenientes das mais variadas atividades humanas. A grande preocupação vem em relação ao descarte inadequado dos resíduos decorrentes desses produtos, o que representa um grave risco para o ambiente e para a saúde humana. Os organismos aquáticos, terrestres e os seres humanos são diretamente afetados pela contaminação através desse resíduo, já pontuado pela Agência de Proteção Ambiental por seu alto potencial tóxico quando despejado no ambiente e justificando a criteriosa tolerância de seu descarte em efluentes (Bendassolli et al. 2003; Dallago et al. 2008; EPA 2018). A disposição de resíduos de prata em efluentes e resíduos sólidos para o meio ambiente está bem estabelecida. Limite de descarte em efluentes líquido é de $0,1 \mathrm{mg} / \mathrm{L}$, segundo a Resolução Consema n 355 (2017) e a Resolução CONAMA $n^{\circ} 357$ (2005), alterada pela Resolução CONAMA n 430 (2011) e para sólidos 5,0 mg/L, segundo a ABNT NBR 10004, Resíduos Sólidos - Classificação (2004) (Silva et al., 2016).

Uma estimativa alarmante da ABETRE (Associação Brasileira de Empresas de Tratamento de Resíduos) confirma que 22\% apenas, de cerca de 2,9 milhões de toneladas de resíduos industriais perigosos gerados anualmente no país, são tratadas adequadamente.

A exposição a compostos de prata e prata pura pode se dar por via oral, dérmica ou por inalação. A prata, apesar de ser encontrada na maioria dos tecidos, não tem função fisiológica conhecida. Em humanos, a ingestão acidental ou intencional de doses elevadas de nitrato de prata pode causar danos corrosivos do trato gastrointestinal, dor abdominal, diarreia, vômitos, convulsões e até morte. Irritação respiratória foi observada após a exposição aguda por inalação de prata ou compostos de deste metal (ATSDR, 1999; Bianchini and Wood, 2003; Science Lab 2018).

Atualmente, é unânime o pensamento que a melhor solução para minimizar o impacto ambiental é o reaproveitamento destes resíduos, aliados á isso, a reutilização e recuperação de materiais de valor agregado como matéria-prima ou como subprodutos têm crescido significativamente nos últimos anos. Mas infelizmente grande parte das empresas, além de instituições de ensino ainda possui dificuldades no gerenciamento destes resíduos, uma vez que - gerador é sempre responsável pelo seu resíduo (Abreu e lamamoto, 2003; Alves et al., 2005; Felisberto et al., 2008; Jardim, 1998; Rodrigues et al., 2018).

Nos laboratórios de pesquisa, controle de qualidade e ensino, a utilização de nitrato de prata é bastante comum, pois muitas análises, tais como determinação de cloretos, concentração de cloreto de amônio, demanda química de oxigênio entre outras são muito comuns (Felisberto et al., 2008; Saran et al., 2015; Songsasen e Poowanathai, 2002).

As análises com nitrato de prata, além de gerar resíduos com alta concentração deste metal, também tem um valor comercial muito 
alto, por se tratar de um reagente nobre (Songsasen e Poowanathai, 2002).

Com base nesse contexto, 0 presente trabalho teve como objetivo a recuperação da prata contida em resíduos analíticos para posterior obtenção de nitrato de prata aplicando os conceitos de sustentabilidade somente utilizando reagentes vencidos e reciclando os mesmos.

\section{MATERIAIS E MÉTODOS}

Os resíduos de prata foram obtidos da central analítica da Escola Estadual Técnica São João Batista (Montenegro - RS), provenientes de diversos processos como análise de cloretos, concentração de cloreto de amônio e demanda química de oxigênio. Os reagentes analíticos utilizados na reação de obtenção do nitrato de prata são todos vencidos, com exceção dos utilizados para determinação do grau de pureza do produto final obtido. Os reagentes utilizados foram: cloreto de sódio (grau alimentício), hidróxido de amônio, ácido nítrico, glicose, frutose, hidróxido de sódio, hidróxido de potássio e ácido clorídrico, sendo todos fora do prazo de validade. Para determinação do grau de pureza foi utilizado nitrato de prata PA (Synth), ácido nítrico PA (Nuclear), sulfato férrico amoniacal (Synth) e tiocianato de amônio 0,1 M (Merck).

\subsection{Preparação dos Resíduos Analíticos de Prata}

Para o tratamento do resíduo, foi adicionado cloreto de sódio (NaCl) (grau alimentício), precipitando a prata que estava solúvel, na forma de cloreto de prata. Em seguida, foi separado 0 precipitado do sobrenadante por filtração em filtro de vidro sinterizado $\mathrm{n}^{\circ}$ 4. $O$ precipitado foi lavado com água destilada quente (Murphy et al., 1991).

\subsubsection{Obtenção do Cloreto de Prata}

Em um béquer de $250 \mathrm{~mL}$ foram pesados $2,5 \mathrm{~g}$ de resíduos analíticos de prata e adicionado sobre o mesmo $50 \mathrm{~mL}$ de água. A solução foi agitada por alguns minutos e em seguida foi adicionado $50 \mathrm{~mL}$ hidróxido de amônio, mantendo agitação até completa solubilização dos resíduos de prata. Em seguida foi adicionado mais $50 \mathrm{~mL}$ de água e agitado até completa dissolução. Após foram adicionados lentamente $100 \mathrm{~mL}$ de ácido nítrico/água $(1: 1 \mathrm{v} / \mathrm{v})$ sobre o meio reacional. A reação que ocorre é uma reação exotérmica obtendo um precipitado branco. Sobre a solução foi adicionado $5 \mathrm{~g}$ cloreto de amônio, onde foi obtido o cloreto de prata na forma de precipitado branco. A solução foi filtrada e o precipitado lavado com água destilada e seco a temperatura ambiente (Murphy et al., 1991).

\subsubsection{Obtenção da Prata Metálica}

Para a obtenção da prata metálica a partir do cloreto de prata foram utilizadas cinco metodologias diferentes. As técnicas utilizadas para a redução do cloreto de prata a prata metálica foram reduções com: formaldeído, açúcar grau alimentício, glicose, frutose e zinco metálico.

\subsubsection{Redução com Formaldeído}

Sobre $2,5 \mathrm{~g}$ de cloreto de prata obtido na reação anterior foram adicionados $2,05 \mathrm{~g}$ de hidróxido de sódio em $50 \mathrm{~mL}$ água sob agitação, em um béquer de $250 \mathrm{~mL}$. Em seguida foi adicionado $2 \mathrm{~mL}$ de formol $37 \%$, gota-a-gota. O béquer foi coberto com um vidro de relógio e agitado por uma hora, à temperatura de $70^{\circ} \mathrm{C}$. Posteriormente, a solução foi filtrada em funil sinterizado $n^{\circ} 4$, lavado com água destilada e seca a temperatura ambiente, onde se obteve esferas de prata metálica (Hsu et al., 1996; Murphy et al., 1991; (Songsasen e Poowanathai, 2002). A reação ocorre conforme a equação 1.

$2 \mathrm{AgCl}+3 \mathrm{NaOH}+\mathrm{CH}_{2} \mathrm{O} \rightarrow 2 \mathrm{Ag}+\mathrm{HCO}_{2} \mathrm{Na}+2$ $\mathrm{NaCl}+2 \mathrm{H}_{2} \mathrm{O}(1)$

\subsubsection{Redução com açúcar grau alimentício}

Sobre $2,5 \mathrm{~g}$ de cloreto de prata obtido na reação anterior foram adicionados $1,4 \mathrm{~g}$ de hidróxido de sódio em $50 \mathrm{~mL}$ água sob agitação, em um béquer de $250 \mathrm{~mL}$. Adicionou-se $2 \mathrm{~g}$ de açúcar comercial sobre o meio reacional, cobrindo o béquer com um vidro de relógio e mantendo em agitação por 60 minutos, à temperatura de $60-70^{\circ} \mathrm{C}$. Posteriormente, a solução foi filtrada em funil sinterizado $n^{\circ} 4$, lavado com água destilada e seca a temperatura ambiente, onde se obteve esferas de prata metálica (Hsu et al., 1996; kuya, 1993; Songsasen e Poowanathai, 2002). A reação ocorre conforme a equação 2 .

$2 \mathrm{AgCl}+3 \mathrm{NaOH}+\mathrm{C}_{6} \mathrm{H}_{12} \mathrm{O}_{6} \rightarrow 2 \mathrm{Ag}+\mathrm{C}_{6} \mathrm{H}_{11} \mathrm{O}_{7} \mathrm{Na}$ 
$+2 \mathrm{NaCl}+2 \mathrm{H}_{2} \mathrm{O}(2)$

\subsubsection{Redução com glicose e frutose}

As técnicas de redução por glicose e frutose seguiram o mesmo procedimento da técnica de redução por glicose comercial (2.1.1.2). A única diferença foi a troca do açúcar comercial pela glicose ou frutose, nas mesmas concentrações (Songsasen e Poowanathai, 2002). A reação ocorre conforme a equação 2.

\subsubsection{Redução com zinco metálico}

Em um béquer de $250 \mathrm{~mL}$ contendo $2,5 \mathrm{~g}$ cloreto de prata, adicionou-se $10 \mathrm{~mL}$ de ácido clorídrico 0,01M. Em seguida foram adicionados $0,75 \mathrm{~g}$ de zinco metálico em pó e agitado por $24 \mathrm{~h}$ em agitador magnético, à temperatura ambiente. Após o tempo decorrido, a solução foi filtrada em funil sinterizado $n^{\circ} 4$ onde se obteve esferas de prata metálica. As esferas de prata foram lavadas com solução de ácido sulfúrico $6 \mathrm{M}$, para remover o excesso de zinco metálico, seguido de água (Hsu et al., 1996). A reação ocorre conforme a equação 3.

$$
2 \mathrm{AgCl}+\mathrm{Zn} \rightarrow 2 \mathrm{Ag}+\mathrm{ZnCl}(3)
$$

\subsubsection{Obtenção do Nitrato de Prata}

Após secas, as esferas de prata foram transferidas para um béquer de $250 \mathrm{~mL}$ e adicionado $10 \mathrm{~mL}$ de água, seguido de $10 \mathrm{~mL}$ de ácido nítrico, mantendo em agitação por 1 hora. Após o tempo decorrido, a solução foi filtrada em funil sinterizado $n^{\circ} 4$ para retirar as impurezas e lavado com água destilada. A solução foi transferida para uma cápsula de vidro e concentrada em banho-maria. Depois a cápsula foi transferida para um dessecador contendo sílica gel e escamas de hidróxido de potássio, para neutralizar os vapores ácidos e armazenado a vácuo até completa secagem do nitrato de prata. Para determinação do rendimento, a amostra foi seca em estufa a $105{ }^{\circ} \mathrm{C}$ por 60 minutos e armazenada em dessecador para as etapas posteriores (Amaral et al., 2001; Songsasen e Poowanathai, 2002).

\subsubsection{Análise do grau de pureza do Nitrato de Prata}

Para a determinação do grau de pureza foram pesados $0,3 \mathrm{~g}$ de amostra seca em estufa e dissolvidos em $50 \mathrm{~mL}$ de água. Em seguida, foi adicionado $1 \mathrm{~mL}$ de ácido nítrico P.A. e $1 \mathrm{~mL}$ de indicador de sulfato férrico amoniacal e titulado com tiocianato de amônio $0,1 \mathrm{M}$ até $\mathrm{o}$ aparecimento de uma leve coloração laranja avermelhado. O cálculo do grau de pureza foi realizado a partir da seguinte fórmula:

$$
\% \text { de pureza }=\frac{\mathrm{V}(\mathrm{ml}) \cdot \mathrm{M} \cdot \mathrm{F} \cdot 16,987}{P(g)}
$$

onde $\mathrm{V}$ é o volume $(\mathrm{mL}), \mathrm{M}$ molaridade e $\mathrm{F}$ o fator do tiocianato de amônio e $P$ é o peso em gramas da amostra de nitrato de prata. Este foi o único procedimento que não se utilizou reagentes vencidos, para garantir uma caracterização mais precisa. A análise foi realizada em triplicata.

\section{RESULTADOS E DISCUSSÃO:}

Para o tratamento do resíduo analítico foi adicionado inicialmente, cloreto de sódio em excesso, para garantir que toda a prata que estava solúvel precipitasse de na forma de cloreto de prata. O precipitado de cloreto de prata, com outros precipitados também de prata foram filtrados e secos a temperatura ambiente.

A etapa seguinte foi realizada para purificar o resíduo analítico, que estava nas mais diferentes formas de precipitado. Nesta etapa foi adicionado e hidróxido de amônio para solubilizar todo o precipitado de prata na forma de diaminprata, também chamado de diaminoargentato de prata, conforme a equação 4.

$$
\mathrm{AgX}+2 \mathrm{NH}_{3} \rightarrow \mathrm{Ag}\left(\mathrm{NH}_{3}\right)_{2}^{+}+\mathrm{X}^{-}(4)
$$

O precipitado de prata pode estar em diferentes formas, com contra-íons diferentes de cloreto. Esta etapa é importante para garantir que todo o precipitado esteja na forma de cloreto de prata, conforme necessário para as próximas etapas. Depois foi adicionado ácido nítrico, seguido de cloreto de amônio. Primeiramente todo diaminprata passou para a forma de nitrato de prata e depois foi precipitado na forma de cloreto de prata, conforme as equações 5 e 6 . 
$\mathrm{Ag}\left(\mathrm{NH}_{3}\right)_{2}{ }^{+}+\mathrm{HNO}_{3}+2 \mathrm{H}_{2} \mathrm{O} \rightarrow \mathrm{AgNO}_{3}+2 \mathrm{NH}_{3}+$ $\mathrm{H}_{3} \mathrm{O}^{+}$(5)

$$
\mathrm{AgNO}_{3}+\mathrm{NH}_{4} \mathrm{Cl}+\rightarrow \mathrm{AgCl}+\mathrm{HNO}_{3}(6)
$$

Nesta etapa verifica-se a formação de um precipitado muito branco e a solução ficou turva, indicando que todas as impurezas ficaram na fração aquosa. Depois a solução foi filtrada e o precipitado lavado com água destilada a quente.

A obtenção da prata metálica, do nitrato de prata e a determinação do grau de pureza do reagente obtido estão apresentados na Tabela 1.

Todas as metodologias apresentaram um rendimento similar na obtenção da prata metálica, com exceção do método empregando glicose. Todos os métodos apresentaram um rendimento em torno de $80 \%$ e o método que emprega glicose apresentou $75 \%$. Considerando que todos os reagentes estavam vencidos e o intuito era o reaproveitamento dos mesmos, a glicose poderia estar com uma degradação superior aos demais.

$\mathrm{Na}$ análise de rendimento na obtenção do nitrato de prata, o método com formaldeído e com frutose apresentaram os maiores rendimentos, $\quad 96,53 \%$ e $96,66 \%$, respectivamente. A glicose apresentou um rendimento intermediário, 92,62 \% e o zinco e o açúcar comercial foram os menores valores observados, 90,67\% e 90,28\%, respectivamente.

A única etapa que não foram reaproveitados reagentes vencidos foi na determinação do grau de pureza, do nitrato de prata obtido.

Os graus de pureza variaram de 96,17 a $99,27 \%$, sendo os resultados mais altos para a metodologia empregando formaldeído, açúcar grau alimentício e glicose, conforme Tabela 1. As metodologias empregando frutose e zinco apresentaram os menores valores 96,99 e $96,27 \%$, respectivamente.

Para a recuperação de resíduos de laboratório e reagentes vencidos em escolas de nível médio e técnico na obtenção de nitrato de prata, todas as metodologias se apresentaram satisfatórios.

A metodologia empregando zinco é uma técnica que necessita de mais tempo que as demais. Enquanto todas as demais técnicas necessitam de uma hora para a obtenção da prata metálica, a metodologia empregando zinco necessita de 24 horas. Além disto, é necessária a adição de ácido sulfúrico para a remoção do excesso de zinco metálico.

\section{CONCLUSÕES:}

Foram testadas cinco técnicas simples para obtenção de nitrato de prata a partir de resíduos analíticos e reagentes vencidos com bons rendimentos. A técnica empregando zinco se apresentou a menos viável que as demais, por ser mais demorado, além da necessidade de uma etapa adicional empregando ácido sulfúrico. As variações no rendimento e grau de pureza do nitrato de prata nas técnicas empregando açúcares (frutose, glicose e açúcar grau alimentício), pode ser devido ao grau de pureza dos respectivos reagentes, considerando que todos foram reaproveitados. A metodologia empregando formaldeído, mesmo apresentando bons resultados necessita de cuidados adicionais, pois o reagente é conhecido como potencial carcinogênico. Os procedimentos de reaproveitamento dos resíduos analíticos e reagentes vencidos apresentaram serem sustentáveis, diminuindo os resíduos de laboratório sem causar danos ao meio ambiente. Portanto, esse projeto apresentou ser economicamente viável e ecologicamente correto. Estas técnicas poderão ser potencialmente utilizadas em laboratórios de Instituições de ensino a fim de recuperar os resíduos analíticos transformando-os em produtos para consumo nas aulas práticas, além do desenvolvimento da conscientização ambiental.

\section{REFERÊNCIAS:}

1. http://www.abetre.org.br/. Acessado em: 13.06.2019.

2. ABNT, NBR. 10004: 2004. Resíduos sólidos: Classificação. Associação Brasileira de Normas, 2004.

3. Abreu, D.G., lamamoto, Y., Química Nova, 2003, 26, 582.

4. ADVFN.https://br.advfn.com/investimento s/commodities/prata/introducao. Acessado em 13.06.2018.

5. Agencia para Sustancias Tóxicas y el Registro de Enfermedades. (ATSDR), Reseña Toxicológica de la Plata. Atlanta, 
GA: Departamento de Salud y Servicios Humanos de los EE.UU., Servicio de Salud Pública, 1999.

6. Alves, L.C., Henrique, H.M., Xavier, A.M., Cammarota, M.C., Bioresource Technology, 2005, 96, 1650.

7. Amaral, S.T., Machado, P.F.L., Peralba, M.D.C.R., Camara, M.R., Santos, T.D., Berleze, A.L., Falcão, H.L., Martinelli, M., Gonçalves, R.S., Oliveira, E.R., Brasil, J.L., Aurélio, M., Araújo, M., Borges, A.C.A., Quim. Nova, 2001, 24, 419.

8. Bendassolli, J.A., Tavares, G.A., Flgnoto, R., Rosseti, A.L.R.M., Química Nova, 2003, 26, 578.

9. Bianchini, A., Wood, C.M., Environmental Toxicology and Chemistry, 2003, 22, 1361.

10. Dallago, R.M., Di Luccio, M., Golunski, C., Batistella, L., Engenharia Sanitária e Ambiental, 2008, 13, 121.

11. Felisberto, R., Vieira, L.O., Couto, A., Schuh, R., Albino, C.T., Libardi, D.B., Cunha, A.C.B., Química Nova, 2008, 31, 174.

12. Hsu, P.C., Chiba, Z., Schumacher, B.J., Murguia, L.C., Adamson, M.G., Lawrence Livermore National Lab., CA (United States), 1996.

13. Jardim, F. W., Química Nova, 1998, 21, 671.

14. Kuya, M.K., Química Nova, 1993, 474.

15. Co. de Shanghai GCM, Ltd. http://www.appraisalfp7.eu/20534/canad\%C3\%A1-mineral-deouro-da-tritura-o.html\#. Acessado em 13.06.2018.

16. Modi, A., Shukla, K., Pandya, J., Parmar, K., Emerging Technology and Advanced Engineering, 2012, 599.

17. Murphy, J.A., Ackerman, A.H., Heeren, J. K., Journal of Chemical Education, 1991, 68, 602 .

18. Nakiboğlu, N., Toscali, D., Nisli, G. Turkish Journal of Chemistry, 2003, 27, 127.

19. Ramirez, P.A., Reyes, V.E., Veloz, M.A., International Journal of Electrochemical Science, 2011, 6, 6151.
20. Resolução CONAMA n 357, 2005.

21. Resolução CONAMA n 430, 2011.

22. Resolução CONSEMA n 355, 2017.

23. Rodrigues, C.A., Laurenti, A., Souza, L., Silva, B.E.S., In Towards Green Campus Operations, 2018, 793.

24. Saran, L.M., Giansante, R.H., Silveira, G.A., Matinato, M.G., Duda, R.M., Revista Virtual de Química, 2015, 7, 1072.

25. Science Lab.com. Silver Nitrate MSDS. http://www.sciencelab.com/msds.php?ms dsld=9927411. Acessado em:14.06.2018.

26. Silva, M.G.L., Silva, L.C.S., Mazzé, F.M., Ataíde, M.C.E.S., Holos, 2016, 2, 132.

27. Songsasen, A., Poowanathai, N., Kasetsart J. (Nat. Sci.), 2002, 36, 435.

28. U.S. Environmental Protection Agency. https://www.epa.gov/. acessado em: 14.06.2018. 
Tabela 1. Resultados dos percentuais de prata, nitrato de prata e pureza obtidos.

\begin{tabular}{c|c|c|c}
\hline Metodologias & Prata (\%) & $\mathrm{AgNO}_{3}(\%)$ & Pureza $\left(\mathrm{AgNO}_{3} \%\right)$ \\
\hline Formaldeído & $79,56 \pm 2,32$ & $96,53 \pm 3,83$ & $99,27 \pm 0,38$ \\
Açúcar comercial & $79,62 \pm 0,98$ & $90,28 \pm 2,59$ & $99,29 \pm 0,37$ \\
Glicose & $75,38 \pm 1,27$ & $92,63 \pm 3,43$ & $98,02 \pm 0,65$ \\
Frutose & $79,32 \pm 0,79$ & $96,66 \pm 0,94$ & $96,99 \pm 0,42$ \\
Zinco & $80,23 \pm 0,38$ & $90,67 \pm 1,64$ & $96,17 \pm 0,43$ \\
\hline
\end{tabular}

PERIÓDICO TCHÊ QUÍMICA • www.periodico.tchequimica.com • Vol. 16 N. 31.

- ISSN 1806-0374 (impresso) • ISSN 1806-9827 (CD-ROM) • ISSN 2179-0302 (meio eletrônico) (C) 2019. Porto Alegre, RS. Brasil 